\title{
How water flow, geometry and material properties drive plant
}

\section{movements}

\author{
Richard J Morris ${ }^{1 *}$ and Mark Blyth ${ }^{2}$ \\ ${ }^{1}$ Computational and Systems Biology, John Innes Centre, Norwich, UK \\ ${ }^{2}$ School of Mathematics, University of East Anglia, Norwich, UK \\ richard.morris@jic.ac.uk \\ m.blyth@uea.ac.uk
}

*Corresponding author

\section{Highlight}

This review summarises recent results on reversible plant shape changes that are driven by active water movement.

\begin{abstract}
Plants are dynamic. They adjust their shape for feeding, defence and reproduction. Such plant movements are critical for their survival. We present selected examples covering a range of movements from single cell to tissue level and over a range of timescales. We focus on reversible turgor-driven shape changes. Recent insights into the mechanisms of stomata, bladderwort, the waterwheel and the Venus flytrap are presented. The underlying physical principles (turgor, osmosis, membrane permeability, wall stress, snap buckling, elastic instability) are highlighted and advances in our understanding of these processes are summarised.
\end{abstract}

(C) The Author(s) 2019. Published by Oxford University Press on behalf of the Society for Experimental Biology. All rights reserved. For permissions, please email: journals.permissions@oup.com 


\section{Key words}

Plant biomechanics, nastic movements, turgor, osmosis, membrane permeability, snap buckling, elastic instability, guard cells, stomata, Venus flytrap, bladderwort, waterwheel 


\section{Introduction}

As plants grow they change shape (Harmer and Brooks, 2018). In addition to such irreversible changes, plants carry out a range of reversible shape-shifting activities, moving from one form to another with speeds that span several orders of magnitude (Hill and Findlay, 1981; Geitmann, 2016). These shape changes are critical for processes such as nutrient acquisition, the regulation of water status, or the defence against predators.

There are several ways that plant movements can be classified based on, for instance: the presence of directional dependence on a stimulus (tropism vs nastic motion); the requirement for metabolic energy (active vs passive or osmotic vs hygroscopic); the timescales (fast vs slow); the regularity (oscillatory vs single-event); the utilisation of energy storage (motor vs power-amplification or hydraulic vs elastic instability); the transient nature (reversibility vs irreversibility or elastic vs plastic). Such classifications are useful as they unite different biological systems around key physical parameters and/or mechanisms, allowing ideas to be transferred and extended from the specific to more general cases. Focussing instead on the order of events, a classification scheme for movements was recently put forward based on their temporal succession during development of the plant (Rivière et al., 2017).

Plant shape changes arise from the interaction of water (often through turgor pressure but also hydration, cavitation and capillary action) and the plant cell wall (Geitmann and Ortega, 2009; Dumais and Forterre, 2012). Elastic instabilities or snap-buckling (Skotheim and Mahadevan, 2005) can be exploited when the speed limits imposed by water transport need to be overcome. See the Glossary and the following sections for brief explanations and 
definitions of key terms and Table 1 for which plant movements are associated with which underlying mechanisms.

Growth-related movements have been recently reviewed (Cosgrove, 2018a; Harmer and Brooks, 2018; Kierzkowski and Routier-Kierzkowska, 2019), a distinguishing feature of which is the requirement for cell wall stress relaxation and viscoelastic/plastic behaviour (Cosgrove et al., 1984; Cosgrove, 2016). Other irreversible movements include those that lead to fracture, which like cavitation is a mechanism for the sudden release of stored energy. Explosive seed dispersal relies on fracture (Hofhuis et al., 2016). Whilst the energy storage mechanism is active and involves building up turgor pressure, irreversible movements such as seed dispersal typically take place by passive mechanisms. Passive movements are driven by hydration or dehydration, often as a consequence of air humidity (Forterre, 2013).

Here, building on excellent recent reviews (Burgert and Fratzl, 2009; Stahlberg, 2009; Dumais and Forterre, 2012; Forterre, 2013; Guo et al., 2015; Oliver et al., 2016; Charpentier et al., 2017), we provide an update and present new results on old questions (Darwin and Darwin, 1880) relating to reversible shape changes (Hill and Findlay, 1981). We will discuss what the key parameters are for such movements and how the plant can manipulate these parameters to reversibly change shape. We focus on the common underlying principles and recent developments on understanding the physics of these processes. 


\section{Recent insights into active reversible shape changes}

Shape changes require force to carry out the work associated with the movement. Motors are devices that convert a form of energy into mechanical work and, by analogy, cells that expand (or contract) to generate movement are called 'motor cells'. Reversible active plant movements are driven by motor cells. If driven solely by motor cells, the speed of movement would be equal to the speed of the motor, which is limited by water transport between cells or within tissues. This leads to a characteristic time scale known as the poroelastic time, which is a function of the transport distance, viscosity, hydraulic permeability, and the elastic shear modulus (Skotheim and Mahadevan, 2005). To move faster than the limits of water transport requires further mechanisms and plants exploit elastic instabilities (Forterre et al., 2005; Skotheim and Mahadevan, 2005; Joyeux et al., 2011) and motors, springs and latches (Ilton et al., 2018) to do so.

Plant movements are driven by swelling and shrinking of cells (motor cells). Motor cells govern the movements of stomata, circadian cycles in leaf and stem movements, and the folding leaflets of touch-sensitive plants. Some movements require additional elements in addition to motors. The physical principles of such movements (Stahlberg, 2009; Dumais and Forterre, 2012; Forterre, 2013; Guo et al., 2015; Oliver et al., 2016) include osmosis which powers motor cells (Hill and Findlay, 1981), elastic instabilities (Forterre et al., 2005;

Skotheim and Mahadevan, 2005) and cell wall mechanics (Cosgrove, 2018b). Although ideas for macroscopic biophysical principles have been put forward, these are still under debate and the cellular and microscopic details of these processes are remain poorly understood. In the following we provide a brief overview of recent developments into the physics of some of 
the core processes that govern plant movements and blend in progress on unravelling specific biological systems to exemplify the potential mechanisms.

\section{Osmosis}

Water flow into plant cells is commonly explained by osmosis. Osmosis is a consequence of the difference in chemical potentials that arise on either side of a semipermeable membrane, Figure 1, due to different solute concentrations. The chemical potential is the change in the internal energy of the system with respect to particle number and is measured in Joule (J) per mole. Perhaps because a gradient in the chemical potential is seen as the driving force, it is often stated that osmosis is driven by diffusion (down a presumed concentration gradient of water). Yet this view is misleading (Kramer and Myers, 2013). Thermodynamics provides the state variables for a system in equilibrium but does not give a mechanistic view of how the system goes from one state to another. The difference in chemical potential can be explained thermodynamically by the entropy of mixing, yet entropy is not a driving force (Lambert, 2002; Grandy, Jr., 2008). Bidirectional diffusion through biological membranes certainly occurs yet it cannot account for the experimentally determined membrane permeabilities (Ray, 1960). Indeed it was this discrepancy that led to the Nobel Prize winning discovery of water channels, aquaporins (Agre, 2006). Pressure-driven flow has been suggested since the 1930s. Ray (Ray, 1960) provided a compelling case against the prevailing idea at the time, which was that water diffused driven by the difference in osmotic and turgor pressure (sometimes called 'diffusion pressure deficit'), and developed a theory for bulk water flow through (at the time yet to be discovered) water channels in biological membranes. 
Building on ideas suggested by Borg (Borg, 2003), Bowler (Bowler, 2017) put forward an elegant explanation of the mechanics underlying osmotic pressure. The pressure of an ideal gas is defined as the time-average force per unit area exerted by particles as they bounce off the walls of a vessel. Ideal gases have no interaction between particles. If interactions are present, their potential energy leads to a reduction in pressure compared to an ideal gas. The virial theorem of classical mechanics relates kinetic and potential energies $(\mathrm{J})$ of particles to pressure $(\mathrm{Pa})$. The pressure of a real fluid can thus be separated into contributions from the kinetic energy of the particles in the fluid and the potential energy from their interaction (Bowler, 2017). For a liquid the interactions between particles is substantial. The pressure in chamber 1, on the left of the semi-permeable membrane in Figure 1, can be seen as a consequence of the kinetic energy of water molecules (w), $\mathrm{E}_{1, \mathrm{w}}^{\mathrm{kin}}$, and the potential energy between water molecules (ww), $\mathrm{E}^{\mathrm{pot}}{ }_{1 \text { ww }}$. The index 1 refers to chamber 1 . The kinetic energy of water can be large but this positive energy is largely cancelled by the large negative (attractive) interaction between molecules that occurs in liquids. The pressure in chamber 2, on the right of the semi-permeable membrane in Figure 1, can be seen as a consequence of the kinetic energy of water molecules (w), $\mathrm{E}_{2, \mathrm{w}}^{\mathrm{kin}}$, the kinetic energy of the solute molecules $(\mathrm{s}), \mathrm{E}_{2, \mathrm{k}}^{\mathrm{kin}}$, the potential energy between water molecules (ww), $\mathrm{E}_{2, \mathrm{ww}}^{\mathrm{pot}}$, the potential energy between solute molecules (ss), $\mathrm{E}_{2, \mathrm{ss}}^{\mathrm{pot}}$, and the potential energy between water and solute

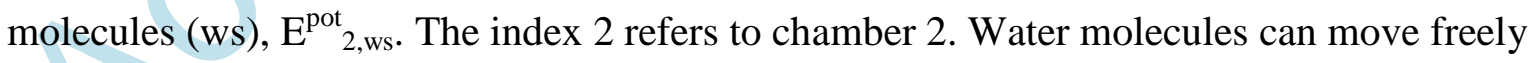
through the semi-permeable membrane, whereas solute molecules cannot and are thus limited to chamber 2. At equilibrium the driving force on the water molecules across the membrane must be equal in both directions, resulting in no net flow. The net pressure on the water molecules on each side of the membrane depends on the sum of the kinetic and potential energies relating to water molecules on that side: $\mathrm{E}_{1, \mathrm{w}}^{\mathrm{kin}}+\mathrm{E}_{1 \text {,ww }}^{\mathrm{pot}}$ in chamber 1 giving rise to $\mathrm{P}_{1 \mathrm{w}}$ and $\mathrm{E}^{\mathrm{kin}}{ }_{2, \mathrm{w}}+\mathrm{E}^{\mathrm{pot}}{ }_{2, \mathrm{ww}}+\mathrm{E}^{\mathrm{pot}}{ }_{2, \mathrm{ws}}$ in chamber 2 giving rise to $\mathrm{P}_{2 \mathrm{w}}$ (note that $\mathrm{E}^{\mathrm{pot}}{ }_{2, \mathrm{ss}}$ contributes 
to the overall pressure in chamber 2 but does not act on water molecules and thus does not contribute to $\mathrm{P}_{2 \mathrm{w}}$ ). We can understand osmotic flow intuitively by referring back to the pressures acting on water molecules. The pressures before adding solute arise from the energies, $E_{1, \mathrm{w}}^{\mathrm{kin}}+E_{1, \mathrm{ww}}^{\mathrm{pot}}$ in chamber 1 and $E_{2, \mathrm{w}}^{\mathrm{kin}}+E_{2 \text {,ww }}^{\mathrm{pot}}$ in chamber 2 which must be balanced at equilibrium. After addition of solute, a potential energy term arises between water and solute, $E^{\text {pot }}$,ws, and the water related energies become $E_{2, w}^{\text {kin }}+E_{2, w w}^{\text {pot }}+E^{\text {pot }}{ }_{2, w s}$. Water will thus flow from chamber 1 to chamber 2 , driven by the resulting pressure difference (largely caused by $\mathrm{E}^{\mathrm{pot}}{ }_{2, \mathrm{ws}}$ ), until $\mathrm{P}_{1 \mathrm{w}}-\mathrm{P}_{2 \mathrm{w}}=0$. Pressure-driven flow is known as bulk flow.

In the state where $\mathrm{P}_{1 \mathrm{w}}=\mathrm{P}_{2 \mathrm{w}}$, there remain uncompensated energy terms in chamber $2, \mathrm{E}_{2, \mathrm{~s}}^{\mathrm{kin}}+$ $\mathrm{E}^{\mathrm{pot}}$ 2,ss, that give rise to a pressure (resulting in a higher force, $\mathrm{F}_{2}>\mathrm{F}_{1}$ in Figure 1, being required on the right side to balance this pressure). This is the osmotic pressure $\mathrm{P}^{\text {os }}$ which is the hydrostatic pressure difference between two chambers of solution of different solute concentrations that are separated by a semipermeable membrane. In equilibrium, the difference in force, $\mathrm{F}_{2}-\mathrm{F}_{1}$ corresponds to the osmotic pressure, $\mathrm{P}^{\mathrm{os}}$, times the area of the piston, Figure 1. If $F_{2}$ is increased beyond this point, then the pressure on the water molecules in chamber 2 will be higher than in chamber 1 and water will flow from chamber 2 to chamber 1 until the pressures are equilibrated (reverse osmosis). Note, that nothing in the above considerations limits the application to liquids and indeed osmotic pressure can be observed also for gases.

For dilute solutions where the solute molecules are far apart and the potential energy between them, $\mathrm{E}_{2, \mathrm{ss}}^{\mathrm{pot}}$, is negligible, the osmotic pressure arises only from the kinetic energy of the solute, thus leading to an approximate relationship that reflects the behaviour of an ideal gas (no interactions) which is known as the van't Hoff law, $\mathrm{P}^{\mathrm{os}}=\mathrm{RTc}_{\text {solute. The van't Hoff law }}$ says that in a dilute solution, the osmotic pressure in $\mathrm{Pa}, \mathrm{P}^{\mathrm{os}}$, is proportional to the 
temperature in Kelvin, $\mathrm{T}$, and the concentration of the solute in mole, $\mathrm{c}_{\text {solute }}$, and $\mathrm{R}$ is the ideal gas constant $\left(\mathrm{R}=8.314 \mathrm{~J} \cdot \mathrm{mol}^{-1} \cdot \mathrm{K}^{-1}\right)$. To influence osmosis, the plant can thus modify the flux of ions (in particular potassium and chloride) (Blatt, 2000; Hedrich, 2012; Wang et al., 2017) and make changes in metabolism to alter osmotic compound concentrations (Argiolas et al., 2016) or modify the permeability of the membrane for water through aquaporin gating (Törnroth-Horsefield et al., 2006; Alleva et al., 2012; Maurel et al., 2015; Rodrigues et al., 2017). Brownian motion and diffusion of water and solute will, of course, take place in both chambers but the case against osmosis being driven by diffusion of solvent down a presumed water concentration gradient is nearly sealed, despite occasional counter-arguments leaking through (Nelson, 2017).

\section{Cell wall mechanics}

The cell wall plays a key role in plant movements. Osmosis leads to water influx into the cell, which via the stress $\left(\mathrm{N} / \mathrm{m}^{2}\right)$ exerted by the cell wall gives rise to turgor pressure. The Lockhart-Ortega equation (Ortega, 1985) describes cell volume changes, $\mathrm{dV} / \mathrm{dt}\left(\mathrm{m}^{3} / \mathrm{s}\right)$, as a function of turgor pressure, $\mathrm{P}(\mathrm{Pa})$, and turgor pressure changes, $\mathrm{dP} / \mathrm{dt}(\mathrm{Pa} / \mathrm{s})$, by treating the cell wall as a linear viscoelastic material,

$(1 / \mathrm{V}) \mathrm{dV} / \mathrm{dt}=\Phi \cdot\left[\mathrm{P}-\mathrm{P}_{\mathrm{c}}\right]+(1 / \varepsilon) \mathrm{dP} / \mathrm{dt}$

The first term on the right describes irreversible extension under the assumption that the cell wall behaves like a linear viscous fluid (Ortega uses the somewhat confusing term 'viscoelastic' here). A better term is perhaps 'viscoplastic' for this type of behaviour. $\Phi$ is a 
constant representing the extensibility of the cell wall $\left(\mathrm{s}^{-1} \mathrm{~Pa}^{-1}\right), \varepsilon$ is the elastic bulk modulus of the cell $\left(\mathrm{Pa}^{-1}\right)$ and $\mathrm{P}_{\mathrm{c}}$ is the critical turgor pressure $(\mathrm{Pa})$ which corresponds to the turgor pressure at which the induced stress in the cell wall reaches the yield stress and beyond which irreversible deformation occurs, Figure 2. Below the yield stress the material is assumed to behave reversibly. Any ductile material will possess a yield stress, Figure 2, which arises from molecular rearrangements in the material under tension. For cell walls these molecular rearrangements can be mediated by expansins (Cosgrove, 2016) and enzymatically catalysed to change microfibril connectivity (Zhang et al., 2017). Thus, creep of cell walls during growth is a regulated process. The induced stress will depend on the geometry of the cell and the stresses in the neighbouring cells. This induced stress in the wall will, in general, be a tensor as opposed to a scalar quantity such as pressure. Likewise, the yield stress is best described by a tensor to reflect the mechanical anisotropy of the cell wall. For materials that change their properties under deformation, such as cell walls which are enzymatically loosened (Zhang et al., 2017), nonlinear viscoelasticity might be more appropriate. The second term on the right hand side of the Lockhart-Ortega equation describes the elastic response under the assumption that stress is proportional to turgor pressure. Recent currently non peer reviewed - work has demonstrated deviations from this single cell linear viscoelastic model, showing that volume changes can be both positively and negatively correlated with turgor (Long et al., 2018), depending on tissue topology (cell connectivity). Although for the examples presented here, we have focussed on reversible behaviour of the cell wall (as opposed to growth), it is known that several biochemical processes are important for what is placed under the umbrella of elastic behaviour. For instance, membrane trafficking (Shope and Mott, 2006; Jezek and Blatt, 2017; Bourdais et al., 2018), gene expression (McAdam et al., 2016), regulated water flux (Hachez et al., 2017), ion channel activity (Blatt, 2000; Kim et al., 2010; Hedrich, 2012) and metabolism (Karnik et al., 2017; 
Jezek and Blatt, 2017) have been shown to play a role in stomata opening (see below). Whilst the Lockhart-Ortega model has been highly successful, recent observations (Zhang et al., 2017; Long et al., 2018; Yi et al., 2018; Ye et al., 2018) suggest that refinements may be required (Jensen and Fozard, 2015; Ali and Traas, 2016; Marom et al., 2017; Oliveri et al., 2018; Kierzkowski and Routier-Kierzkowska, 2019). Given the number of biochemical processes involved in cell wall modification it seems reasonable to assume that the plant will be able to adjust the parameters in these material models to fine-tune responses.

\section{Force-velocity trade-offs and snap-buckling}

The movements described here are driven by water, either directly or in the motor activity that builds up tension and stores energy. This provides a useful means to analyse the timescales of such movements (Skotheim and Mahadevan, 2005). Plant movements can be grouped into swelling/shrinking (hydraulic), snap buckling and explosive fracture (elastic instabilities) (Skotheim and Mahadevan, 2005). Another way of thinking of this is whether or not energy storage is required, as has been elegantly described in Llorens et al. (Llorens et $a l ., 2016)$. The energy required to move a part of the plant is equal to the work done by this movement: work $=$ force $\mathrm{x}$ distance. To carry out work in a given time requires that sufficient energy can be made available within that timeframe, which is the power needed to drive the process: power $=$ energy $/$ time. As energy $/$ time $=$ force $\mathrm{x}$ distance $/$ time $=$ force $\mathrm{x}$ velocity a given power supply results in a trade-off between the force that can be generated and the speed of movement (Ilton et al., 2018). Thus, depending on the involved masses, strategies for energy storage and rapid release may be required. Strategies employed by plants include 'motors' (reversible turgor-driven cell expansion), 'springs' and 'latches' (elastic instabilities, fracture, cavitation). Using abstract models of these three components, (Ilton et al., 2018) 
analyse under which conditions which strategy is best suited. For the fern cavitation catapult described in Llorens et al. (Llorens et al., 2016), the motor is driven by evaporation which stores elastic energy in the annular cells leading to 'water tension'. This extraordinary metastable state of negative absolute water pressure (Herbert et al., 2006; Menzl et al., 2016), which is key for water transport through the xylem, is prone to cavitation which provides a latch mechanism (Llorens et al., 2016). Ilton et al. (Ilton et al., 2018) list further latch mechanisms by which this energy is released, which include geometric instabilities for the Venus flytrap and bladderworts (see below). We can thus analyse plant movements in terms of their length and timescales but also in terms of their force-velocity trade-offs and the underlying mechanisms for work input, energy storage and release. Mathematical analysis of elastic instabilities suggests that energy release should occur at speeds comparable to the speed of sound. However, this is faster than what is observed and the slower speed has been hypothesised to result from energy dissipation (Forterre et al., 2005). A recent study on such snap-through instabilities, however, demonstrates that the slower than expected rate of energy release at such transitions can be explained without energy dissipation (Gomez et al., 2017). This study suggests that this dynamical behaviour could be tuned, for instance by changing the viscoelasticity or poroelasticity of the system (Gomez et al., 2017).

\section{Simple pressure-driven movements}

\section{Stomata}

Stomata are formed by a pair of cells called guard cells. Stomata reversibly change their shape, Figure 3, in response to various biotic and abiotic stimuli (Assmann and Jegla, 2016) by adjusting their internal pressure. Stomata sizes vary but are in the region of tens of 
micrometres and the typical timescales for opening and closing are in the order of several minutes to tens of minutes. Guard cell pressure can be influenced via osmosis by ion fluxes and metabolism (Karnik et al., 2017; Jezek and Blatt, 2017). Models of the regulation of osmotic gradients (Pantin and Blatt, 2018) have been highly successful and now bridge scales between micro- and macroscopic behaviour and between active and passive responses (Wang et al., 2017).

Recent biomechanical modelling has focussed on the geometry and material properties of cell walls (Rui et al., 2016, 2018; Shtein et al., 2017; Woolfenden et al., 2017; Carter et al., 2017; Marom et al., 2017; Yi et al., 2018) and confirmed old ideas on the importance of anisotropic wall properties and in particular circumferentially aligned cellulose microfibrils. To determine the key biomechanical ingredients for stomatal movement, (Woolfenden et al., 2017; Marom et al., 2017) used simplified models with idealised geometries. To account for the large strains and wall thicknesses, Woolfenden et al. (Woolfenden et al., 2017) moved beyond linear elasticity and thin-shell models in their study. Consistent with previous work they found only a small impact from local cell wall thickness differences. Their work suggested that strain-stiffening of the cell wall matrix may explain experimental pressureaperture curves (Franks et al., 2001). This explanation is minimal in that no further parameters are required but of course other scenarios are possible (Bidhendi and Geitmann, 2018). Yi et al. (Yi et al., 2018) extended the analysis of shape beyond the usual idealisation and using boundary conditions derived from experimental measurements for their FEM simulations, investigated heterogeneities in guard cell shape. They used their model to identify the contribution of cell wall components (different classes of polysaccharides) on the biomechanical properties. Using a combination of FEM simulations and analytical solutions, (Marom et al., 2017) investigated cell wall anisotropy, the geometry and cell wall components. Using their analytical approach they proposed a method for calculating elastic 
properties from experimental data (Marom et al., 2017), allowing for significant speedups compared to the computational scheme for inferring the properties via optimization (Woolfenden et al., 2017). Biomechanical simulations suggested that whilst the kidneyshaped geometry of the stomata complex already restrains (limits) length changes to around 5 $\%$ (Woolfenden et al., 2017), constraining (fixing) the stomata length can enhance the conversion of turgor pressure to aperture. How the plant might implement this idea is not clear. Atomic force microscopy (AFM) revealed a significant stiffening at the guard cell poles (Carter et al., 2017), but whether or not this is related to 'fixing' the guard cell length remains to be shown. Whilst the AFM measurements were perpendicular to the actual direction of strain and care must be taken in their interpretation, this polar stiffening may reflect a biomechanical constraint in length. Using biochemical analyses, this stiffening could be related to pectin de-esterification (Carter et al., 2017), an observation consistent with previous studies (Amsbury et al., 2016). These findings are discussed in further detail in a recent review on stomatal biomechanics (Woolfenden et al., 2018).

In such simplified approaches, the turgor pressure is commonly taken as an external parameter. Thus, to gain a more comprehensive picture of guard cell biomechanics, the regulation of turgor pressure needs to be considered. Models for turgor pressure generation via ion fluxes, metabolism and thermodynamics (Wang et al., 2017) could be used to drive such biomechanical models.

\section{Movements that require energy storage}

\section{The Venus flytrap}

One of the most studied fast movements in plants is the closing of the Venus flytrap, Dionaea muscipula. The Venus flytrap consists of a pair of modified leaves that form lobes, Figure 4, 
that upon stimulation, can shut within fractions of a second (Forterre et al., 2005). This speed can be achieved by exploiting the existence of bi-stable states. In the open state, the lobes are curved inwards in the direction parallel to the midrib, Figure 4. Triggering the trap changes the curvature in the lobes perpendicular to the midrib. It has been suggested that this perpendicular curvature change introduces a bi-stability in the system (two stable states separated by a potential barrier). Mathematically the closed state ceases to exist for further changes to the perpendicular curvature and the system moves into a state in which the lobes change their parallel curvature and bulge outwards, Figure 4. Using high-speed imaging with stereoscopic reconstruction, Forterre et al. (Forterre et al., 2005) computed local curvatures on the leaf surface during closure. Strain field measurements were carried out and key parameters such as the angular velocity and time delays were determined and used for theoretical models of thin shell dynamics. They treated the leaf as a poroelastic material and used an energy balance equation to fit to their data and study the physics of snap dynamics. This coupling of imaging, geometrical analysis and mechanical modelling, allowed the authors to unravel the macroscopic mechanism of the Venus flytrap and demonstrate how snap-buckling between open and closed state could explain the trap's fast closure. The lobe curvature changes from positive in the open state to negative in the closed state with the rapid transition being a consequence of the bistable nature of the system, Figure 5. However, whilst the proposed bistability exhibits hysteresis (does not behave symmetrically and is not strictly reversible), it is not clear why opening and closing can have such different speeds. Alternative models have been proposed (Volkov et al., 2007, 2013; Markin et al., 2008) that do not rely on snap buckling.

After closure, the plant secretes an acidic hydrolase mixture to digest the prey (Scherzer et al., 2017). Evolutionary modelling based on optimising trade-offs for different types of behaviour and trap parameters, suggests that the Venus flytrap is highly selective for its prey 
(Lehtinen, 2018). The trap can remain closed for several hours or days before reopening occurs (Hill and Findlay, 1981). In terms of the associated energetic states, the Venus flytrap behaves perhaps more like a bicycle slap bracelet than an umbrella in that work is required to reset the trap, thus resulting in very different timescales for opening and closing. Although the prey may have a different take on the reversibility of the whole process, the plant shape change itself can be viewed as reversible. Triggering is achieved by mechanical stimulation of touch-sensitive hairs on the surface. The system requires two stimulations to trigger and snap and further stimulation (activated by prey movement) to close fully (Hill and Findlay, 1981; Guo et al., 2015). Electrical stimulation can be used to replace the mechanical triggering and results in the same behaviour (Volkov et al., 2007), suggesting that hairs also induce an electrical signal. Indeed, the touch-sensitive hairs can induce an action potential (Hill and Findlay, 1981; Volkov et al., 2008, 2011,2013; Hedrich and Neher, 2018). The counting mechanism required for closure is thought to be conveyed by such action potentials which induce calcium releases that become additive if the stimulations are sufficiently close in time $(<30 \mathrm{~s})$. Whilst the precise cellular mechanism for initiating the change in curvature remains elusive, the existence of action potentials during closing suggests a role for the membrane voltage in transporting potassium ions out of cells on the lobe surfaces and by osmosis causing them to deflate. This deflation would change the mechanical rigidity of the leaf and cause the outward bending curvature state to become unstable and move the system to the closed state. Further details on the role of action potentials for trap closure can be found in recent reviews (Hedrich and Neher, 2018; Volkov, 2019).

\section{The waterwheel plant}


The waterwheel plant, Aldrovanda vesiculosa, is related to the Venus flytrap and has a similar morphology but with some key differences (Poppinga and Joyeux, 2011). The snaptrap also consists of two lobes, Figure 6, yet unlike the Venus flytrap these lobes do not significantly change curvature during closing. Furthermore, closing motion has been reported to be smooth and continuous, suggesting that buckling, for which movement is very rapid (abrupt) would be expected, is unlikely to be the underlying mechanism (Westermeier et al., 2018). So, despite the evolutionary relationship between the waterwheel plant and the Venus fly trap and their similar prey trapping behaviour, the details of the underlying mechanisms may be distinct (smooth elastic relaxation for the waterwheel plant and an abrupt elastic instability for the Venus flytrap). Triggering of the trap leads to potassium fluxes in the region that connects the two lobes that give rise to a rapid loss of turgor in those cells (motor cells). This midrib section goes from straight to curved, Figure 6, which results in trap closure (Poppinga and Joyeux, 2011). Using a combination of high-speed motion capture microscopy, kinematical analyses and FEM modelling, Westermeier et al. (Westermeier et $a l ., 2018$ ) could gain new insights into the closing mechanism. The imaging and kinematics analysis allowed for trap closure speeds to be determined (several tens of $\mathrm{m} / \mathrm{s}$ depending on the ecotype) as well as lobe angles and midrib deformation. Cutting experiments allowed the authors to infer regions of pre-stress (tension and compression) which were compared with their FEM simulations. The lobe material was approximated by an isotropic linear elastic model with a Young's modulus of $10 \mathrm{MPa}$ and a Poisson ratio of 0.3 . The midrib zone was assumed to be stiffer with a Young's modulus of $30 \mathrm{MPa}$. Different models were investigated, with and without pre-stress and with and without turgor changes to evaluate key drivers for the closing mechanisms. Whereas previous reports based on the poroelastic time suggest that a purely hydraulic mechanism may be possible (Skotheim and Mahadevan, 2005; Joyeux, 2013), this work lends support for the hypothesis of 'kinematic amplification' 
(Poppinga and Joyeux, 2011) and shows that turgor pressure changes leading to the release of stored energy in the form of pre-stress are responsible for actuation (Westermeier et al., 2018). Energy being stored in the midrib in form of prestress which upon triggering changes curvature whilst releasing energy is, nevertheless, suggestive of a buckling mechanism. The smooth nature of the transition is surprising but could be caused by dampening. Alternatively, the timescales are consistent with a turgor driven alternation of the midrib geometry. Further research is required that builds on these recent studies to elucidate the detailed physical principles underlying the these shape changes.

\section{Bladderworts}

Aquatic bladderworts, eg Utricularia inflata, are a large family of carnivorous plants. The actual bladder is several millimetres long and can suck in prey in about one millisecond (Singh et al., 2011). Speeds of $1 \mathrm{~m} / \mathrm{s}$ have been measured and accelerations exceed several hundreds of $\mathrm{g}$ (Westermeier et al., 2017). Similar to the Venus flytrap, such speeds are achieved by an elastic instability (Vincent et al., 2011b; Vincent and Marmottant, 2011; Poppinga et al., 2013; Forterre, 2013). However, despite this similarity, there are several differences and also several open questions. The trap consists of the bladder with a trap door that can be triggered by hairs that sense the prey. It is thought that cells continuously pump out water to generate a lower pressure within the bladder compared to the exterior (Hill and Findlay, 1981). This pressure differential of around $17 \mathrm{kPa}$ draws the surrounding bladder walls inwards, Figure 7. The trap door locks the bladder opening in a configuration that is doubly curved and that upon triggering induces the door to buckle (Joyeux et al., 2011). This instability opens the trap, water (and prey) is rapidly sucked in due to the pressure differential 
and the bladder bulges out due to the water influx. The trap door closes and after digestion of the prey the trap resets itself by pumping out water. Mechanical models of the bladder (Vincent et al., 2011c), the trap door (Joyeux et al., 2011) and their combination with hydrodynamics (Llorens et al., 2012) have been used to successfully reproduce key features of bladderwort dynamics, including spontaneous firing (Vincent et al., 2011a). These models approximate the bladder shape by a deformable cylinder and the trap door by an elastic circular disc. Bladder inflation and deflation are accounted for in the model by volume changes that vary between a maximum volume and a resting volume as a function of pressure. Experimentally, the evidence for the deflating mechanism is contradictory. Pumping out is thought to be achieved by active transport of $\mathrm{Cl}^{-}$ions in gland cells and although changes in ion fluxes have been reported, suggesting an osmotic mechanism (Llorens et al., 2012), experiments showing that various concentration of sugars and other mixtures are pumped out equally well do not support the osmosis hypothesis for resetting the trap (Hill and Findlay, 1981). Furthermore the initial reports of pressure differentials in the range of 15-18 MPa have not been reproduced (Vincent and Marmottant, 2011). In analogy to simple eye droppers, it's possible that this negative pressure isn't strictly required. When the rubber sack of an eye dropper is pressed it squeezes fluid out but in that squeezed state the fluid pressure inside and outside is the same. The suction mechanism arises from the quick release and the rubber sack returning to its natural shape and thereby rapidly expanding its internal volume which causes a pressure drop and fluid is sucked in. Rather than a preexisting negative pressure giving bladderworts their suction power and fluid influx changing the bladder, it's conceivable that snap-buckling and volume expansion account for fluid intake. Further biomechanical characterisation (Poppinga et al., 2017; Westermeier et al., 2017) coupled with mathematical modelling will help resolve the precise mechanisms for bladder deflation and trap resetting. 


\section{Conclusions}

We have reviewed recent insights into plant movements on a few selected examples. To limit the scope of the review, we have focussed on reversible active movements. However, from a mechanistic perspective the underlying characteristics are common also to other types of movements. We have highlighted biomechanical aspects of these movements and the macroscopic behaviour of the biological systems as well as some recent advances in the physical processes that underlie plant movements.

Ultimately many of the large-scale shape changes mentioned here are consequences of conformational changes of proteins that change the permeability of biological membranes (ion channels, aquaporins). Such protein conformational changes include the gating of ion channels at various membranes that govern ion fluxes and osmolyte concentrations, and aquaporins that regulate bulk water flow in and out of cells. How exactly these microscopic changes can lead to the observed wealth of movements is in many instances an open question.

Recent advances have been achieved through a combination of imaging, biomechanical and kinematical characterisation, and mathematical modelling. As many of these movements are coupled with electrical and chemical signalling and, depending on the questions at hand and the timescales involved, further integration of such aspects might be an important next step forward. Likewise, for the refinement of existing models of the cell wall to reflect our 
developing knowledge and associated data on their structure and dynamics. Linking these above points with genetics and biochemistry will provide a wealth of additional ways to perturb the behaviour to test model predictions and provide molecular characterisation to develop our understanding of plant biomechanics and movements at the cellular level.

Exciting progress is being made on many fronts and our understanding of movements in the presented biological systems, whilst far from complete, is steadily increasing. Likewise, recent advances on the physical processes that underlie plant movements are enhancing our mechanistic insights. By analogy to the ideas presented here, the plant biomechanics community has been steadily building up and storing knowledge such that 'snap-throughs' to new states of more comprehensive understanding are becoming more frequent. We eagerly await future developments in this fast moving field.

\section{Glossary}

Turgor pressure: Pressure is force (measure in Newtons) per unit area $\left(\mathrm{m}^{2}\right)$ and turgor pressure is the force per unit area of the cell wall which arises from the cell contents pushing from within on the plasmamembrane. Hydrostatics is the study of fluids at rest and 'hydrostatic pressure' is thus the pressure of a fluid at rest, and not restricted to the pressure caused only by a gravitational force as is commonly defined. Pressure in typically measured in Pascal $\left(\mathrm{Pa}=\mathrm{N} / \mathrm{m}^{2}\right)$, bar or atmospheres $(\mathrm{atm})$, whereby 1 bar $=10000 \mathrm{~Pa}=0.987 \mathrm{~atm}$. Turgor pressure is the hydrostatic pressure that is generated by the influx of water into a cell and the resulting stretching of the cell wall which exerts a force on the fluid. Mechanical strain $(\mathrm{m} / \mathrm{m})$ causes mechanical stress $\left(\mathrm{N} / \mathrm{m}^{2}\right)$. In equilibrium the force exerted by the cell 
wall onto the fluid must be matched by the force generated by turgor pressure back on the cell wall. For instance, a container full of water under a moveable piston with a weight of 1 $\mathrm{kg}$, will generate a hydrostatic pressure to deliver a force at the surface of the piston to balance the weight of $1 \mathrm{~kg}$. The presence of gravity means that the pressure will vary as a function of height in the container and this pressure need only match the force from the weight at the piston surface. If we now place a weight of 16 tonnes on the piston, the piston will not move (assuming the incompressibility of water) but the hydrostatic pressure will now increase to deliver a force at the surface of the piston that matches the new external force acting on the fluid.

Kinematic amplification: Kinematics is the study of how objects move without reference to the forces driving the movement, i.e. the focus is on geometry. The term 'kinematic amplification' has been introduced in plant biomechanics to describe how a small displacement in the system can yield a large resulting movement. For instance, imagine a seesaw with the pivot close to one end. A small displacement of the end close to the pivot will result in an equal angular change on both sides but a large displacement on the end far from the pivot.

Bistability: In general, this refers to a system with two stable equilibrium states. A system is in equilibrium when neither motion nor internal energy changes with time. A mechanical equilibrium is characterised by the total force and total torque acting on the system being zero. This condition implies no linear or angular acceleration. A system in mechanical equilibrium thus has constant linear and angular velocity, which can be non-zero (dynamic equilibrium) or zero (static equilibrium). Mechanical equilibrium is sometimes defined as the static equilibrium case of no motion. As force is the negative gradient of the potential energy, 
zero force will arise for all stationary points - extrema (minima, maxima) and saddle points in the potential energy. A maximum in the potential energy gives rise to an unstable equilibrium state. A stable equilibrium point is associated with a minimum in the potential energy. The standard example here is to imagine a ball balanced on the top of a hill (unstable) and a ball at the bottom of a valley (stable). A bistable mechanical system has two stable potential energy minima, separated by an energy barrier that will need to be overcome to move from one stable state to another. For instance, to move a light switch from on to off requires a physical force to push the lever from one state to another.

Viscosity: Viscosity can be understood as the friction between layers of fluid and basically describes the resistance of a fluid to shear deformation. It is measured by the ratio between the applied shear stress on a fluid and the gradient in velocity that is induced by this stress. Viscosity plays a key role in determining the fluid behaviour. Flow is often characterised by the Reynolds number which is the ratio of inertial to viscous forces in a fluid. Many (but not all) flows in biological systems have low Reynolds numbers.

Elastic modulus: A material that is deformed upon the application of an external force which returns to its original state once the force is removed is called elastic. Elastic materials offer resistance against deformation. This resistance to deformation can be captured by the appropriate elastic modulus. Young's modulus (often called the elastic modulus) describes the resistance to deform along the direction of opposing forces applied to a body and is defined as the ratio of tensile stress to tensile strain. The bulk modulus (the inverse of compressibility) describes the resistance to deform in all directions under a uniform load - it is an extension of Young's modulus in three dimensions and is defined as the volumetric 
stress to volumetric strain. The shear modulus describes an object's resistance to shear stress is related to viscosity.

Poroelastic time: Poroelasticity describes the interaction between fluid flow and the deformation of an elastic solid within a porous medium. Porous materials are solids with voids or pores such as foams or soil. The behaviour of many biological tissues can be captured well using the equations of poroelasticity theory. Combining the constitutive laws of solid mechanics (an equation that links mechanical stress and strain and in this case also pressure) with the equations of flow through a porous medium, results in an equation that from its mathematical form resembles the diffusion equation. The analogous expression to the diffusion constant is termed the 'poroelastic diffusion constant'. In contrast to a standard diffusion constant, the poroelastic diffusion constant depends on the mechanical properties of the porous elastic solid. This analogy of terms does not imply that fluid transport in porous media is a diffusive process. The timescale for water movement will define how quickly plant movements can occur based solely on hydraulics. The poroelastic time, which depends on the square of the tissue size and the poroelastic diffusion constant, captures this timescale and can be used to classify plant movements. If the timescale of movement is faster than the porelastic time then the movement cannot be explained by hydraulics alone.

Hydraulic permeability: The ability of a fluid to flow through a porous medium is characterised by its permeability. It arises as a proportionality constant in the equation that links flow rate and the pressure gradient and is therefore one of the key parameters for determining the poroelastic time. 
Elastic instability and buckling: Buckling arises when an equilibrium state of an elastic medium becomes unstable. Mathematically, buckling represents a bifurcation. A bifurcation occurs when a smooth change in a key parameter causes a sudden change in the system, essentially changing the stability of the system and leading to a new state. This may have a dramatic effect in the case of a bi-stable system, for example, if one of the stable states either loses stability or ceases to exist. In that case the system may suddenly snap from one state to another, a phenomenon known as `snap-through’ or `snap-buckling’. When a stable point becomes unstable in an elastic system, this is known as an elastic instability. Typical examples are increasing the load on a walking cane until it goes from straight to bent, a perturbation to a bicycle slap bracelet that takes it from a straight elongated configuration to one that wraps around your ankle, or an umbrella being inverted with a gust of wind.

\section{Acknowledgments}

We are grateful to two anonymous reviewers who provided constructive comments and detailed insights that have greatly improved the manuscript. RJM acknowledges support from BBSRC's Institute Strategic Programme on Biotic Interactions underpinning Crop Productivity (BB/J004553/1) and Plant Health (BB/P012574/1). 


\section{References}

Agre P. 2006. The aquaporin water channels. Proceedings of the American Thoracic Society $3,5-13$.

Ali O, Traas J. 2016. Force-Driven Polymerization and Turgor-Induced Wall Expansion. Alleva K, Chara O, Amodeo G. 2012. Aquaporins: Another piece in the osmotic puzzle. FEBS Letters 586, 2991-2999.

Amsbury S, Hunt L, Elhaddad N, Baillie A, Lundgren M, Verhertbruggen Y, Scheller H V, Knox JP, Fleming AJ, Gray JE. 2016. Stomatal Function Requires Pectin De-methylesterification of the Guard Cell Wall. Current biology : CB 26, 2899-2906.

Argiolas A, Puleo GL, Sinibaldi E, Mazzolai B. 2016. Osmolyte cooperation affects turgor dynamics in plants. Nature Publishing Group.

Assmann SM, Jegla T. 2016. Guard cell sensory systems: recent insights on stomatal responses to light, abscisic acid, and CO2. Current Opinion in Plant Biology 33, 157-167.

Bidhendi AJ, Geitmann A. 2018. Finite Element Modeling of Shape Changes in Plant Cells. Plant Physiology 176, 41-56.

Blatt MR. 2000. $\mathrm{Ca}(2+)$ signalling and control of guard-cell volume in stomatal movements. Current opinion in plant biology 3, 196-204.

Borg FG. 2003. What is osmosis? Explanation and understanding of a physical phenomenon. Bourdais G, McLachlan DH, Rickett LM, et al. 2018. The use of quantitative imaging to investigate regulators of membrane trafficking in Arabidopsis stomatal closure. Traffic.

Bowler MG. 2017. The physics of osmotic pressure. European Journal of Physics 38 , 055102.

Burgert I, Fratzl P. 2009. Actuation systems in plants as prototypes for bioinspired devices. Philosophical Transactions of the Royal Society A: Mathematical, Physical and Engineering 
Sciences 367, 1541-1557.

Carter R, Woolfenden H, Baillie A, et al. 2017. Stomatal Opening Involves Polar, Not Radial, Stiffening Of Guard Cells. Current Biology 27, 2974-2983.e2.

Charpentier V, Hannequart P, Adriaenssens S, Baverel O, Viglino E, Eisenman S. 2017. Kinematic amplification strategies in plants and engineering. Smart Materials and Structures 26, 063002.

Colombani M, Forterre Y. 2011. Biomechanics of rapid movements in plants: poroelastic measurements at the cell scale. Computer Methods in Biomechanics and Biomedical Engineering 14, 115-117.

Cosgrove DJ. 2016. Plant cell wall extensibility: connecting plant cell growth with cell wall structure, mechanics, and the action of wall-modifying enzymes. Journal of Experimental Botany 67, 463-476.

Cosgrove DJ. 2018a. Diffuse Growth of Plant Cell Walls. Plant physiology 176, 16-27. Cosgrove DJ. 2018b. Nanoscale structure, mechanics and growth of epidermal cell walls. Current Opinion in Plant Biology 46, 77-86.

Cosgrove DJ, Van Volkenburgh E, Cleland RE. 1984. Stress relaxation of cell walls and the yield threshold for growth: demonstration and measurement by micro-pressure probe and psychrometer techniques. Planta 162, 46-54.

Darwin C, Darwin F. 1880. The Power of Movement in Plants. Cambridge University Press. Dumais J, Forterre Y. 2012. "Vegetable Dynamicks": The Role of Water in Plant Movements. Annual Review of Fluid Mechanics 44, 453-478.

Forterre Y. 2013. Slow, fast and furious: understanding the physics of plant movements. Journal of Experimental Botany 64, 4745-4760.

Forterre Y, Skotheim JM, Dumais J, Mahadevan L. 2005. How the Venus flytrap snaps. Nature 433, 421-5. 
Franks PJ, Buckley TN, Shope JC, Mott K a. 2001. Guard cell volume and pressure measured concurrently by confocal microscopy and the cell pressure probe. Plant physiology $125,1577-84$

Geitmann A. 2016. Actuators Acting without Actin. Cell 166, 15-7.

Geitmann A, Ortega JKE. 2009. Mechanics and modeling of plant cell growth. Trends in Plant Science 14, 467-478.

Gomez M, Moulton DE, Vella D. 2017. Critical slowing down in purely elastic 'snapthrough' instabilities. NATURE PHYSICS | 13.

Grandy, Jr. WT. 2008. Entropy and the Time Evolution of Macroscopic Systems. Oxford University Press.

Guo Q, Dai E, Han X, Xie S, Chao E, Chen Z. 2015. Fast nastic motion of plants and bioinspired structures. Journal of the Royal Society, Interface 12, 0598.

Hachez C, Milhiet T, Heinen RB, Chaumont F. 2017. Roles of Aquaporins in Stomata. Springer, Cham, 167-183.

Harmer SL, Brooks CJ. 2018. Growth-mediated plant movements: hidden in plain sight.

Current Opinion in Plant Biology 41, 89-94.

Hedrich R. 2012. Ion channels in plants. Physiological reviews 92, 1777-811.

Hedrich R, Neher E. 2018. Venus Flytrap: How an Excitable, Carnivorous Plant Works.

Trends in Plant Science 23, 220-234.

Herbert E, Balibar S, Caupin F. 2006. Cavitation pressure in water. Physical Review E 74, 041603.

Hill BS, Findlay GP. 1981. The power of movement in plants: the role of osmotic machines. Quarterly reviews of biophysics 14, 173-222.

Hofhuis H, Moulton D, Lessinnes T, Goriely A, Smith R, Hay Correspondence A. 2016. Morphomechanical Innovation Drives Explosive Seed Dispersal Accession Numbers 
KX063714. Cell 166, 222-233.

Ilton M, Bhamla MS, Ma X, et al. 2018. The principles of cascading power limits in small, fast biological and engineered systems. Science (New York, N.Y.) 360, eaao1082.

Jensen OE, Fozard JA. 2015. Multiscale Models in the Biomechanics of Plant Growth. Physiology 30, 159-166.

Jezek M, Blatt MR. 2017. The Membrane Transport System of the Guard Cell and Its Integration for Stomatal Dynamics. Plant Physiology 174, 487-519.

Joyeux M. 2013. Elastic models of the fast traps of carnivorous Dionaea and Aldrovanda. Physical Review E 88, 034701.

Joyeux M, Vincent O, Marmottant P. 2011. Mechanical model of the ultrafast underwater trap of Utricularia. Physical Review E 83, 021911.

Karnik R, Waghmare S, Zhang B, Larson E, Lefoulon C, Gonzalez W, Blatt MR. 2017. Commandeering Channel Voltage Sensors for Secretion, Cell Turgor, and Volume Control. Trends in Plant Science 22, 81-95.

Kierzkowski D, Routier-Kierzkowska A-L. 2019. Cellular basis of growth in plants: geometry matters. Current Opinion in Plant Biology 47, 56-63.

Kim T-H, Böhmer M, Hu H, Nishimura N, Schroeder JI. 2010. Guard cell signal transduction network: advances in understanding abscisic acid, $\mathrm{CO} 2$, and $\mathrm{Ca} 2+$ signaling. Annual review of plant biology 61, 561-91.

Kramer EM, Myers DR. 2013. Osmosis is not driven by water dilution. Trends in Plant Science 18, 195-197.

Lambert FL. 2002. Disorder - A Cracked Crutch for Supporting Entropy Discussions. Journal of Chemical Education 79, 187.

Lehtinen S. 2018. Understanding the Venus flytrap through mathematical modelling. Journal of Theoretical Biology 444, 1-10. 
Llorens C, Argentina M, Bouret Y, Marmottant P, Vincent O. 2012. A dynamical model for the Utricularia trap. Journal of the Royal Society Interface 9, 3129-3139.

Llorens C, Argentina M, Rojas N, Westbrook J, Dumais J, Noblin X. 2016. The fern cavitation catapult: mechanism and design principles.

Long Y, Cheddadi I, Mirabet V, Dumond M, Godin C, Boudaoud A. 2018. Cellular heterogeneity in pressure and growth emerges from tissue topology and geometry. bioRxiv, 334664.

Markin VS, Volkov AG, Jovanov E. 2008. Active movements in plants: Mechanism of trap closure by Dionaea muscipula Ellis. Plant signaling \& behavior 3, 778-83.

Marom Z, Shtein I, Bar-On B. 2017. Stomatal Opening: The Role of Cell-Wall Mechanical Anisotropy and Its Analytical Relations to the Bio-composite Characteristics. Frontiers in Plant Science 8, 2061.

Maurel C, Boursiac Y, Luu D-T, Santoni V, Shahzad Z, Verdoucq L. 2015. Aquaporins in Plants. Physiological Reviews 95, 1321-1358.

McAdam SAM, Sussmilch FC, Brodribb TJ. 2016. Stomatal responses to vapour pressure deficit are regulated by high speed gene expression in angiosperms. Plant Cell and Environment 39, 485-491.

Menzl G, Gonzalez MA, Geiger P, Caupin F, Abascal JLF, Valeriani C, Dellago C. 2016. Molecular mechanism for cavitation in water under tension. Proceedings of the National Academy of Sciences of the United States of America 113, 13582-13587.

Nelson PH. 2017. Osmosis and thermodynamics explained by solute blocking. European biophysics journal : EBJ 46, 59-64.

Oliver K, Seddon A, Trask RS. 2016. Morphing in nature and beyond: a review of natural and synthetic shape-changing materials and mechanisms. Journal of Materials Science 51, 10663-10689. 
Oliveri H, Traas J, Godin C, Ali O. 2018. Regulation of plant cell wall stiffness by mechanical stress: a mesoscale physical model. Journal of Mathematical Biology.

Ortega JK. 1985. Augmented growth equation for cell wall expansion. Plant physiology 79, $318-20$.

Pantin F, Blatt MR. 2018. Stomatal Response to Humidity: Blurring the Boundary between Active and Passive Movement. Plant Physiology 176, 485-488.

Poppinga S, Daber LE, Westermeier AS, Kruppert S, Horstmann M, Tollrian R, Speck

T. 2017. Biomechanical analysis of prey capture in the carnivorous Southern bladderwort (Utricularia australis). Scientific Reports 7.

Poppinga S, Joyeux M. 2011. Different mechanics of snap-trapping in the two closely related carnivorous plants Dionaea muscipula and Aldrovanda vesiculosa. Physical Review E 84, 041928.

Poppinga S, Masselter T, Speck T. 2013. Faster than their prey: New insights into the rapid movements of active carnivorous plants traps. BioEssays 35, 649-657.

Ray PM. 1960. On the Theory of Osmotic Water Movement. Plant physiology 35, 783-95.

Rivière M, Derr J, Douady S. 2017. Motions of leaves and stems, from growth to potential use. Physical Biology 14, 051001.

Rodrigues O, Reshetnyak G, Grondin A, Saijo Y, Leonhardt N, Maurel C, Verdoucq L. 2017. Aquaporins facilitate hydrogen peroxide entry into guard cells to mediate ABA- and pathogen-triggered stomatal closure. Proceedings of the National Academy of Sciences of the United States of America 114, 9200-9205.

Rui Y, Chen Y, Kandemir B, Yi H, Wang JZ, Puri VM, Anderson CT. 2018. Balancing Strength and Flexibility: How the Synthesis, Organization, and Modification of Guard Cell Walls Govern Stomatal Development and Dynamics. Frontiers in Plant Science 9, 1202. Rui Y, Yi H, Kandemir B, Wang JZ, Puri VM, Anderson CT. 2016. Integrating cell 
biology, image analysis, and computational mechanical modeling to analyze the contributions of cellulose and xyloglucan to stomatal function. Plant Signaling \& Behavior 11, e1183086. Scherzer S, Shabala L, Hedrich B, et al. 2017. Insect haptoelectrical stimulation of Venus flytrap triggers exocytosis in gland cells. Proceedings of the National Academy of Sciences $114,4822-4827$.

Shope JC, Mott KA. 2006. Membrane trafficking and osmotically induced volume changes in guard cells. Journal of Experimental Botany 57, 4123-4131.

Shtein I, Shelef Y, Marom Z, Zelinger E, Schwartz A, Popper ZA, Bar-On B, HarpazSaad S. 2017. Stomatal cell wall composition: distinctive structural patterns associated with different phylogenetic groups. Annals of Botany 119, 1021-1033.

Singh AK, Prabhakar S, Sane SP. 2011. The biomechanics of fast prey capture in aquatic bladderworts. Biology letters 7, 547-50.

Skotheim JM, Mahadevan L. 2005. Physical Limits and Design Principles for Plant and Fungal Movements. Science 308, 1308-1310.

Stahlberg R. 2009. The phytomimetic potential of three types of hydration motors that drive nastic plant movements. Mechanics of Materials 41, 1162-1171.

Steudle E. 1989. [16] Water flow in plants and its coupling to other processes: An overview. Methods in Enzymology 174, 183-225.

Törnroth-Horsefield S, Wang Y, Hedfalk K, Johanson U, Karlsson M, Tajkhorshid E, Neutze R, Kjellbom P. 2006. Structural mechanism of plant aquaporin gating. Nature 439, $688-694$.

Vico G, Manzoni S, Palmroth S, Katul G. 2011. Effects of stomatal delays on the economics of leaf gas exchange under intermittent light regimes. New Phytologist 192, 640652.

Vincent O, Marmottant P. 2011. Carnivorous Utricularia: The buckling scenario. Plant 
Signaling \& Behavior 6, 1752-1754.

Vincent O, Roditchev I, Marmottant P. 2011a. Spontaneous Firings of Carnivorous Aquatic Utricularia Traps: Temporal Patterns and Mechanical Oscillations (T Waigh, Ed.). PLoS ONE 6, e20205.

Vincent O, Weisskopf C, Poppinga S, Masselter T, Speck T, Joyeux M, Quilliet C, Marmottant P. 2011b. Ultra-fast underwater suction traps. Proceedings of the Royal Society B: Biological Sciences 278, 2909-2914.

Vincent O, Weisskopf C, Poppinga S, Masselter T, Speck T, Joyeux M, Quilliet C, Marmottant P. 2011c. Ultra-fast underwater suction traps. Proceedings. Biological sciences 278, 2909-14.

Volkov AG. 2019. Signaling in electrical networks of the Venus flytrap (Dionaea muscipula Ellis). Bioelectrochemistry 125, 25-32.

Volkov AG, Adesina T, Jovanov E. 2007. Closing of venus flytrap by electrical stimulation of motor cells. Plant signaling \& behavior 2, 139-45.

Volkov AG, Adesina T, Markin VS, Jovanov E. 2008. Kinetics and mechanism of Dionaea muscipula trap closing. Plant physiology 146, 694-702.

Volkov AG, Harris SL, Vilfranc CL, Murphy VA, Wooten JD, Paulicin H, Volkova MI, Markin VS. 2013. Venus flytrap biomechanics: Forces in the Dionaea muscipula trap. Journal of Plant Physiology 170, 25-32.

Volkov AG, Pinnock M-R, Lowe DC, Gay MS, Markin VS. 2011. Complete hunting cycle of Dionaea muscipula: consecutive steps and their electrical properties. Journal of plant physiology 168, 109-20.

Wang Y, Hills A, Vialet-Chabrand SR, Papanatsiou M, Griffiths H, Rogers S, Lawson T, Lew V, Blatt MR. 2017. Unexpected Connections between Humidity and Ion Transport Discovered using a Model to Bridge Guard Cell-to-Leaf Scales. The Plant Cell, 
tpc.00694.2017.

Westermeier AS, Fleischmann A, Müller K, Schäferhoff B, Rubach C, Speck T, Poppinga S. 2017. Trap diversity and character evolution in carnivorous bladderworts (Utricularia, Lentibulariaceae). Scientific Reports 7, 12052.

\section{Westermeier AS, Sachse R, Poppinga S, Vögele P, Adamec L, Speck T, Bischoff M.}

2018. How the carnivorous waterwheel plant ( Aldrovanda vesiculosa) snaps. Proceedings of the Royal Society B: Biological Sciences 285, 20180012.

Woolfenden HC, Baillie AL, Gray JE, Hobbs JK, Morris RJ, Fleming AJ. 2018. Models and Mechanisms of Stomatal Mechanics. Trends in Plant Science 23, 822-832.

\section{Woolfenden HC, Bourdais G, Kopischke M, Miedes E, Molina A, Robatzek S, Morris}

RJ. 2017. A computational approach for inferring the cell wall properties that govern guard cell dynamics. The Plant Journal 92, 5-18.

Ye D, Kiemle SN, Rongpipi S, Wang X, Wang C, Cosgrove DJ, Gomez EW, Gomez ED. 2018. Resonant soft X-ray scattering reveals cellulose microfibril spacing in plant primary cell walls. Scientific Reports 8, 12449.

Yi H, Rui Y, Kandemir B, Wang JZ, Anderson CT, Puri VM. 2018. Mechanical Effects of Cellulose, Xyloglucan, and Pectins on Stomatal Guard Cells of Arabidopsis thaliana. Frontiers in Plant Science 9, 1566.

Zhang T, Vavylonis D, Durachko DM, Cosgrove DJ. 2017. Nanoscale movements of cellulose microfibrils in primary cell walls. Nature Plants $\mathbf{3}, 17056$. 
Table 1 Selected reversible plant movements, their characteristic parameters, and potential mechanisms. If movements occur slower than the poroelastic time, then water transport is in principle a possible explanation. For movements faster than the poroelastic time, mechanisms other than hydraulics are required. Note that whilst possible mechanisms are listed, these are neither exhaustive nor yet proven in many cases.

* For single cells, the poroelastic time is equivalent to the cell relaxation time, computed here for a guard cell size of $30 \mu \mathrm{m}$.

\begin{tabular}{|c|c|c|c|c|}
\hline $\begin{array}{l}\text { Biological } \\
\text { system }\end{array}$ & $\begin{array}{l}\text { Timescale of } \\
\text { fastest } \\
\text { movement } \\
\text { (order of } \\
\text { magnitude) }\end{array}$ & $\begin{array}{l}\text { Poroelastic } \\
\text { time }\end{array}$ & $\begin{array}{l}\text { Possible } \\
\text { mechanisms }\end{array}$ & References \\
\hline Stomata & $100 \mathrm{~s}$ & $0.5 \mathrm{~s}^{*}$ & Osmosis & $\begin{array}{l}\text { (Steudle, } \\
\text { 1989; Vico et } \\
\text { al., 2011) }\end{array}$ \\
\hline Venus flytrap & $1 / 10 \mathrm{~s}$ & $0.4 \mathrm{~s}$ & $\begin{array}{l}\text { Osmosis; snap } \\
\text { buckling }\end{array}$ & $\begin{array}{l}\text { (Skotheim } \\
\text { and } \\
\text { Mahadevan, } \\
\text { 2005; } \\
\text { Colombani } \\
\text { and Forterre, } \\
\text { 2011) }\end{array}$ \\
\hline $\begin{array}{l}\text { Waterwheel } \\
\text { plant }\end{array}$ & $1 / 100 \mathrm{~s}$ & $0.004 \mathrm{~s}$ & Osmosis & $\begin{array}{l}\text { (Skotheim } \\
\text { and }\end{array}$ \\
\hline
\end{tabular}




\begin{tabular}{|c|c|c|c|c|}
\hline & & & & $\begin{array}{l}\text { Mahadevan, } \\
\text { 2005) }\end{array}$ \\
\hline Bladderwort & $1 / 1000 \mathrm{~s}$ & 0.05 & $\begin{array}{l}\text { Osmosis; snap } \\
\text { buckling }\end{array}$ & $\begin{array}{l}\text { (Skotheim } \\
\text { and } \\
\text { Mahadevan, } \\
\text { 2005) }\end{array}$ \\
\hline
\end{tabular}




\section{Figure legends}

Figure 1 Osmosis drives cell swelling and shrinking. If two chambers that are separated by a semipermeable membrane (that allows for passage of water molecules but not solute) have different solute concentrations, water will flow from the chamber of lower solute concentration (1) to the chamber of higher solute concentration (2) and a pressure difference between the two sides emerges. This pressure difference is known as the osmotic pressure and is a direct consequence of the additional kinetic energy (of the solute molecules) and the additional potential energy (between solute molecules) in chamber 2. A larger force is required on piston 2 than on piston 1 to balance the osmotic pressure and keep the system in equilibrium. Using the viral theorem of classical mechanics, which describes the relationship between kinetic and potential energy of particles and pressure, allows the movement of water to be understood in terms of energetic differences acting on water molecules that give rise to a pressure difference that drives bulk flow. When the pressure on water is equal in both chambers, the net flow of water is zero and the resulting total pressure difference is the osmotic pressure. See main text for further details.

Figure 2 The strain-stress curve for a ductile material (such as steel). This plot shows how a ductile material responds to tension (pulling force). The material stretches with increasing load which is characterised by the relative length change (strain, $x$-axis). The pulling force results in internal forces in the material which are described by the tensile force per area (stress, y-axis). Materials typically have a limited region where stress and strain are linearly proportional (linear elasticity) before nonlinear effects and molecular rearrangements kick in. For cell walls, molecular rearrangements can be regulated and enzymatically catalysed. 
Figure 3 Stomata opening is driven by osmosis. Stomata are formed by a pair of motor cells (guard cells). The top view of a guard cell pair is approximately elliptical. Turgor increase within the guard cells forces them apart. Circumferentially aligned microfibrils restrain guard cell cross-section and encourage the cell to expand in length, leading to a bulging out that opens the stomatal pore. The geometry limits stomatal complex length changes to a few percent. Fixing the stomatal complex length enhances the opening for a given pressure change. Opening and closing can take several minutes to tens of minutes.

Figure 4 The Venus flytrap closes through an elastic instability. The Venus flytrap consists of two lobes that are connected by a midrib. In the open state the lobes are curved inwards. Upon triggering the stable state corresponding to this curvature vanishes and the system moves rapidly through snap-buckling to a state in which the lobes face outwards. Closing occurs in fractions of a second. Opening can take several hours.

Figure 5 The closing of the Venus flytrap can be viewed as snap-buckling similar to an umbrella being turned inside out. The speed of such transitions for such elastic instabilities is rapid. Note, however, that whilst the change in curvature from one state to another might be qualitatively similar between these examples, the analogy is at best a loose one. In particular, whilst the speed of an umbrella moving from state to state is highly symmetric, this is not the case for the Venus flytrap for which mechanical work is performed to slowly build up energy stored in the form of elastic stress.

Figure 6 The waterwheel plant closes by elastic deformation of the midrib. The waterwheel consists of two lobes and resembles the Venus flytrap, only the curvature of the lobes does 
not change significantly nor go through the same elastic instability. Instead the midrib region changes curvature. The lobes store energy in the form of pre-stress.

Figure 7 Bladderworts open their trap through by snap-buckling. The trap is set by pumping fluid out the bladder which is sealed by a trap door. Upon triggering, the trap door buckles and opens, water and prey are sucked in rapidly as the bladder expand out. Bladderworts are the fastest movements of all carnivorous plants recorded and can capture their prey within milliseconds. 


\section{semipermeable membrane}

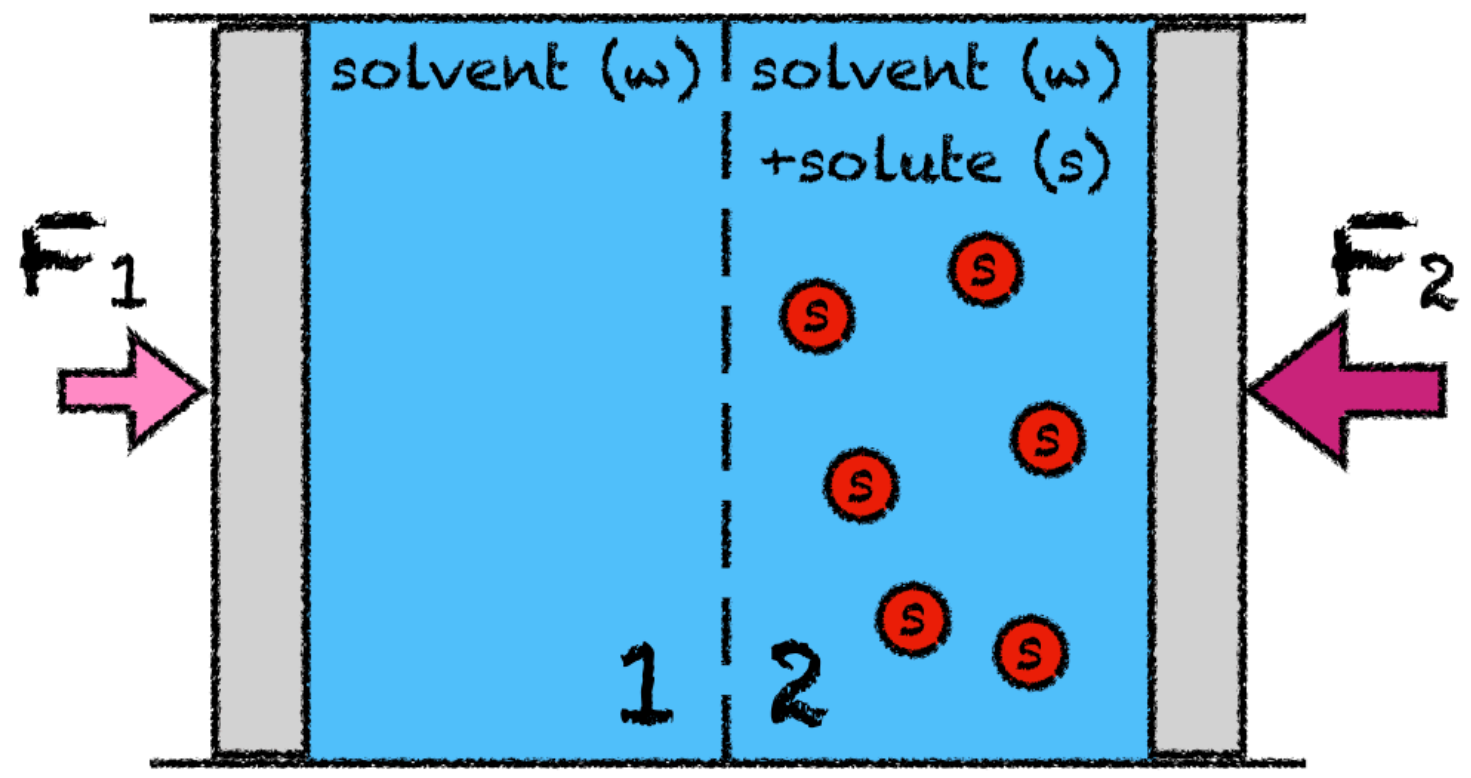

Figure 1 Osmosis drives cell swelling and shrinking. If two chambers that are separated by a semipermeable membrane (that allows for passage of water molecules but not solute) have different solute concentrations, water will flow from the chamber of lower solute concentration (1) to the chamber of higher solute concentration (2) and a pressure difference between the two sides emerges. This pressure difference is known as the osmotic pressure and is a direct consequence of the additional kinetic energy (of the solute molecules) and the additional potential energy (between solute molecules) in chamber 2. A larger force is required on piston 2 than on piston 1 to balance the osmotic pressure and keep the system in equilibrium. Using the viral theorem of classical mechanics, which describes the relationship between kinetic and potential energy of particles and pressure, allows the movement of water to be understood in terms of energetic differences acting on water molecules that give rise to a pressure difference that drives bulk flow. When the pressure on water is equal in both chambers, the net flow of water is zero and the resulting total pressure difference is the osmotic pressure. See main text for further details. 


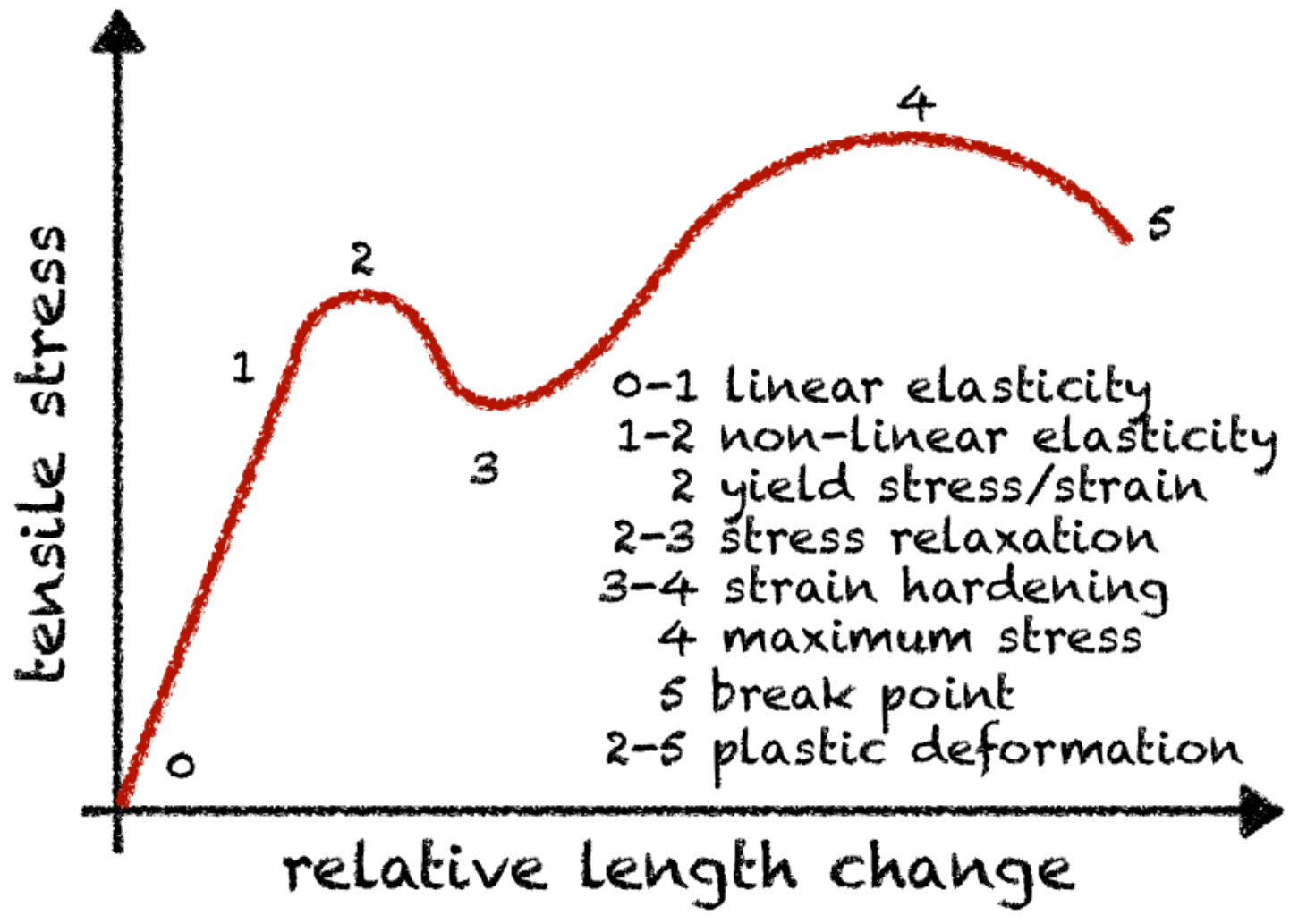

Figure 2 The strain-stress curve for a ductile material (such as steel). This plot shows how a ductile material responds to tension (pulling force). The material stretches with increasing load which is characterised by the relative length change (strain, $\mathrm{x}$-axis). The pulling force results in internal forces in the material which are described by the tensile force per area (stress, y-axis). Materials typically have a limited region where stress and strain are linearly proportional (linear elasticity) before nonlinear effects and molecular rearrangements kick in. For cell walls, molecular rearrangements can be regulated and enzymatically catalysed. 

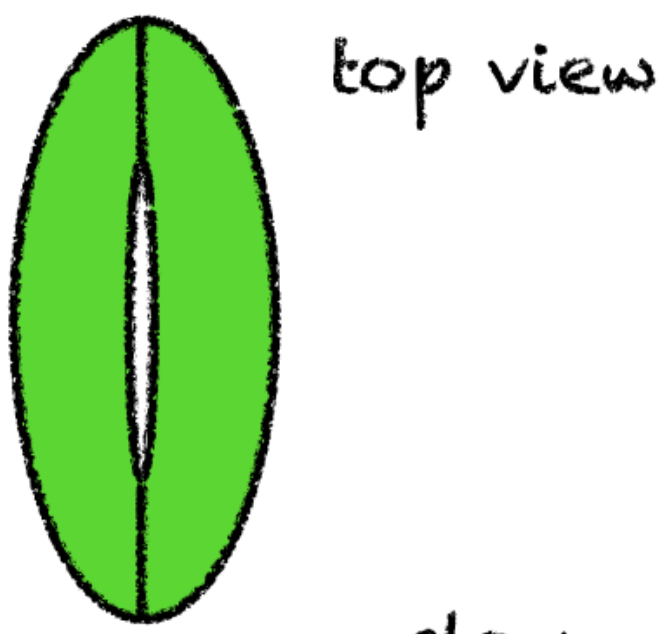

slow
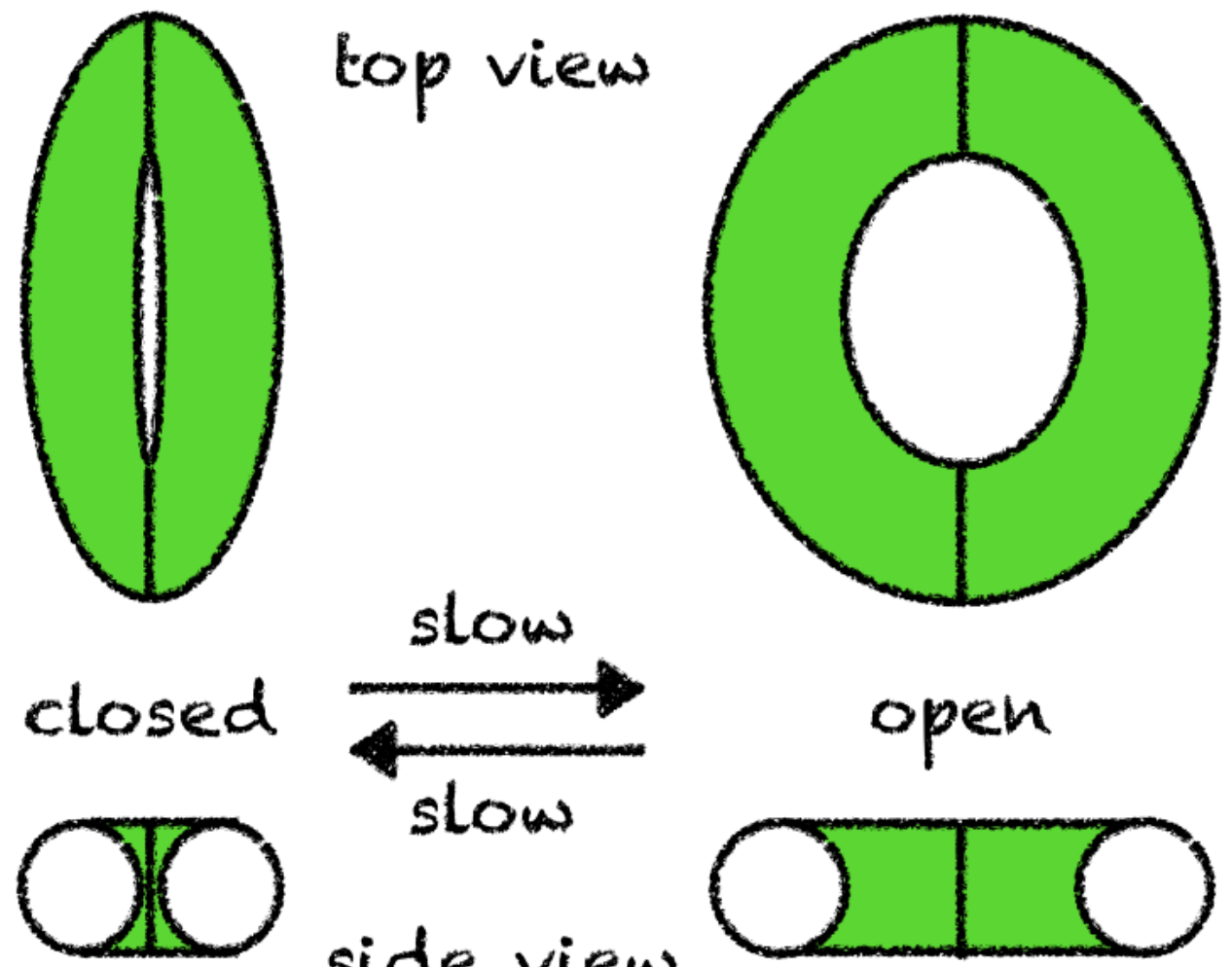

\section{side view}

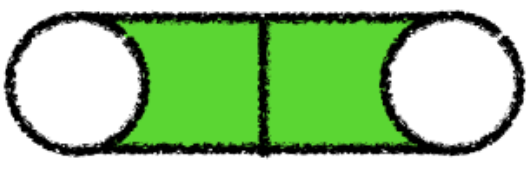

\section{cross section}

Figure 3 Stomata opening is driven by osmosis. Stomata are formed by a pair of motor cells (guard cells). The top view of a guard cell pair is approximately elliptical. Turgor increase within the guard cells forces them apart. Circumferentially aligned microfibrils restrain guard cell cross-section and encourage the cell to expand in length, leading to a bulging out that opens the stomatal pore. The geometry limits stomatal complex length changes to a few percent. Fixing the stomatal complex length enhances the opening for a given pressure change. Opening and closing can take several minutes to tens of minutes. 


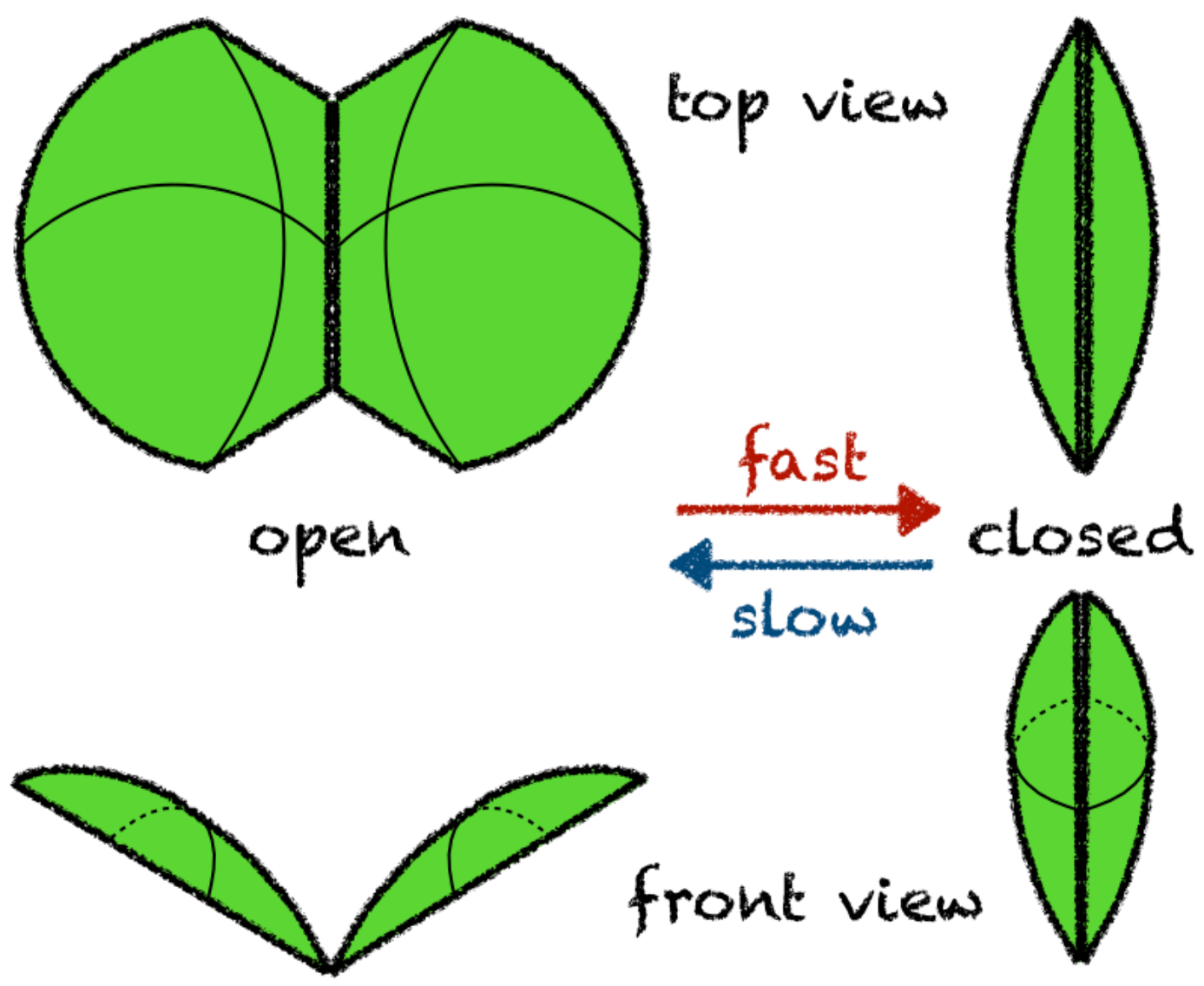

Figure 4 The Venus flytrap closes through an elastic instability. The Venus flytrap consists of two lobes that are connected by a midrib. In the open state the lobes are curved inwards. Upon triggering the stable state corresponding to this curvature vanishes and the system moves rapidly through snap-buckling to a state in which the lobes face outwards. Closing occurs in fractions of a second. Opening can take several hours. 

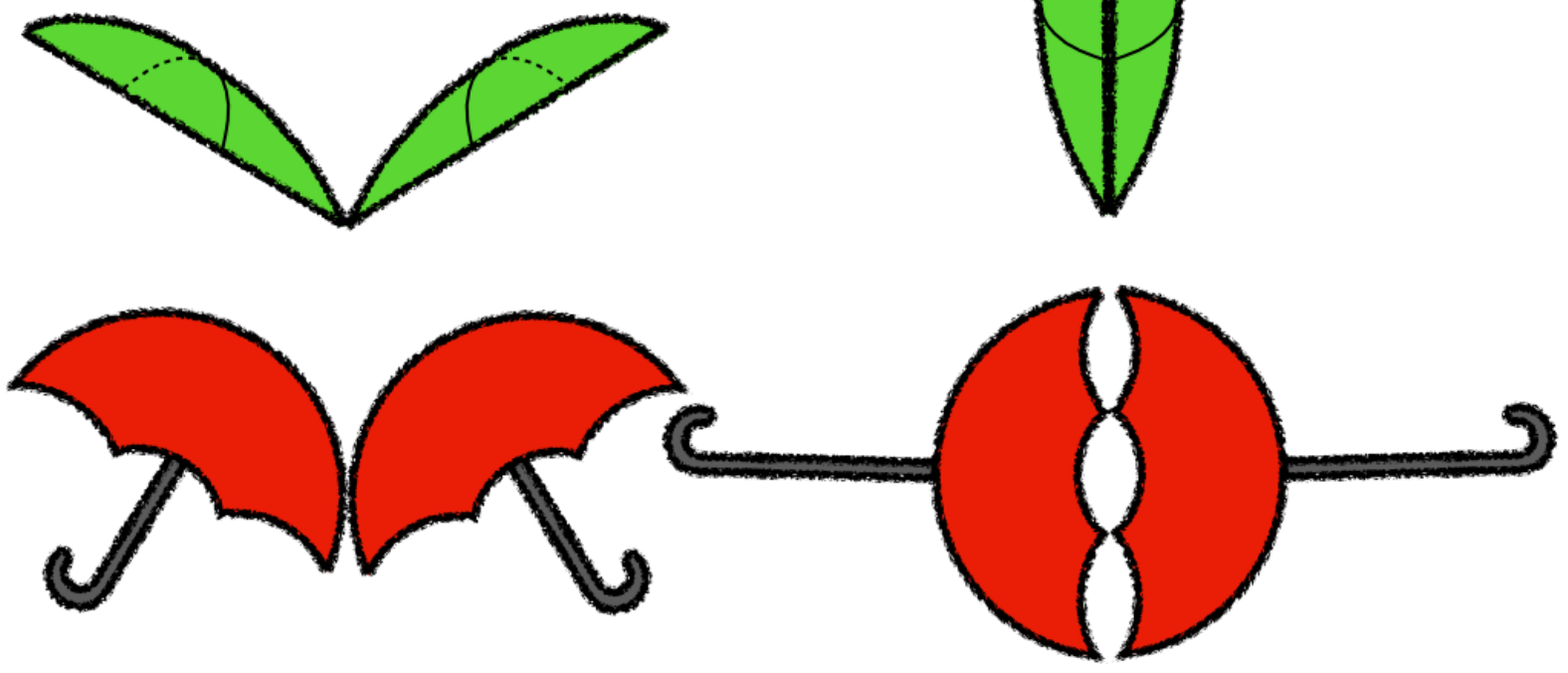

Figure 5 The closing of the Venus flytrap can be viewed as snap-buckling similar to an umbrella being turned inside out. The speed of such transitions for such elastic instabilities is rapid. Note, however, that whilst the change in curvature from one state to another might be qualitatively similar between these examples, the analogy is at best a loose one. In particular, whilst the speed of an umbrella moving from state to state is highly symmetric, this is not the case for the Venus flytrap for which mechanical work is performed to slowly build up energy stored in the form of elastic stress. 


\section{front view}

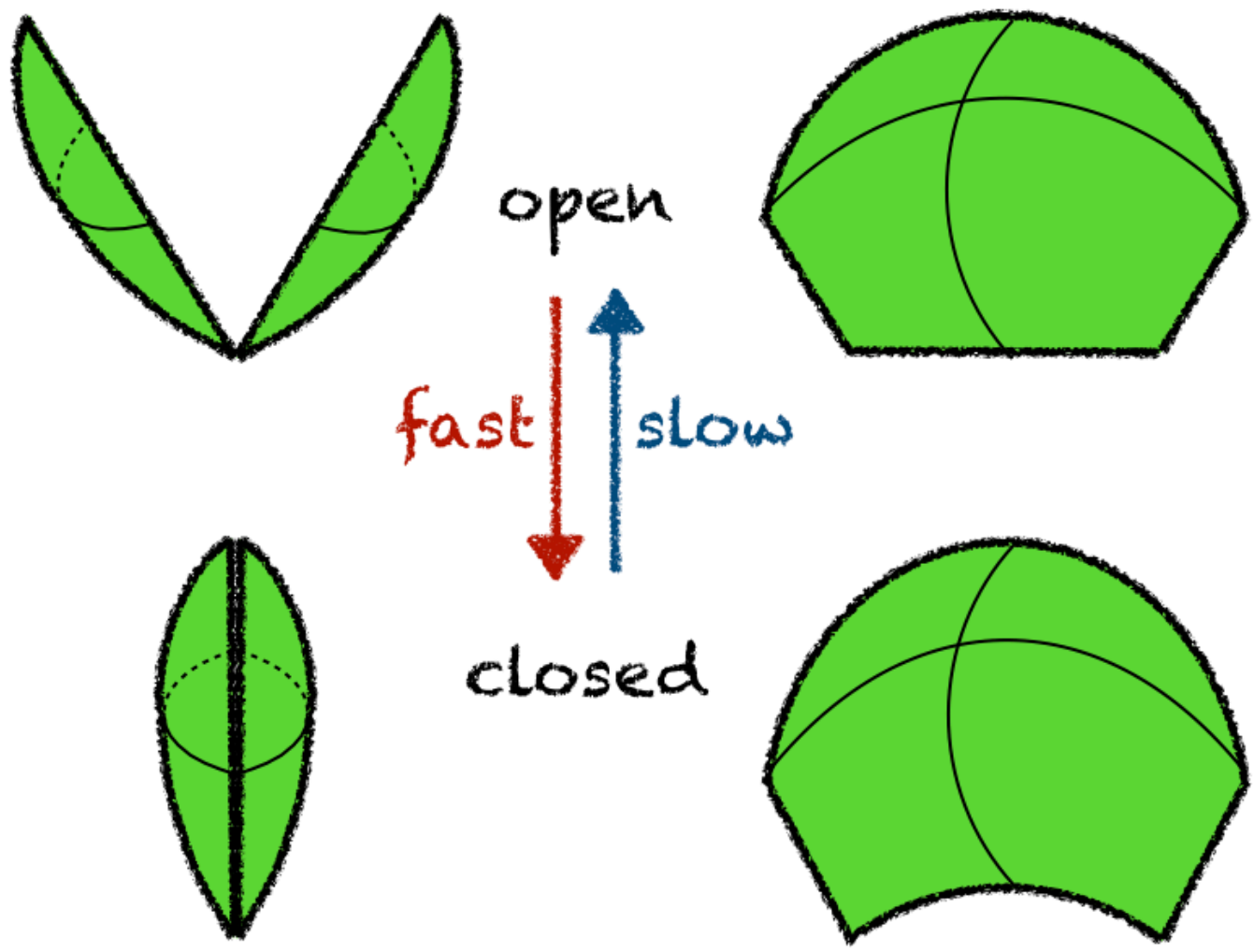

Figure 6 The waterwheel plant closes by elastic deformation of the midrib. The waterwheel consists of two lobes and resembles the Venus flytrap, only the curvature of the lobes does not change significantly nor go through the same elastic instability. Instead the midrib region changes curvature. The lobes store energy in the form of pre-stress. 


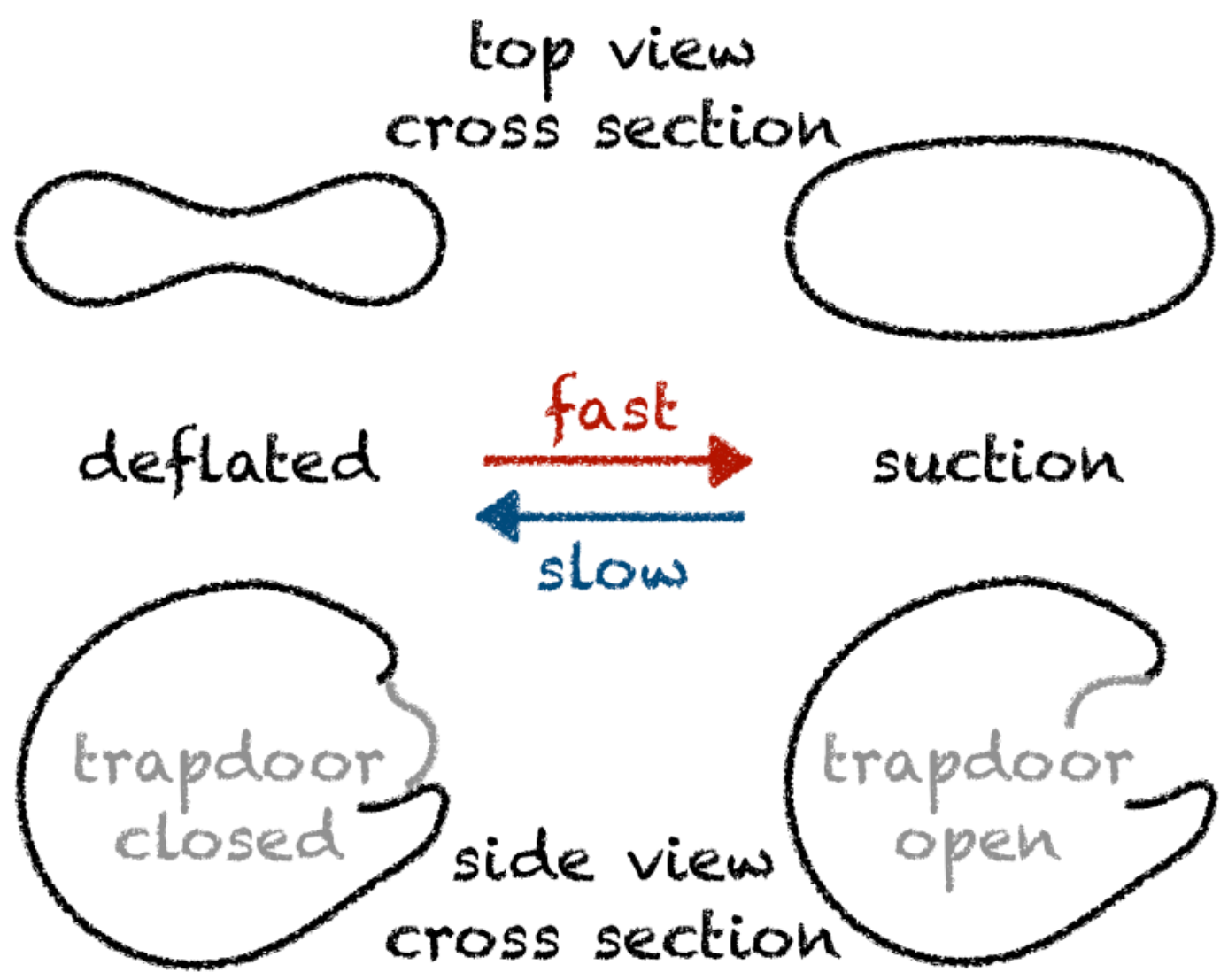

Figure 7 Bladderworts open their trap through by snap-buckling. The trap is set by pumping fluid out the bladder which is sealed by a trap door. Upon triggering, the trap door buckles and opens, water and prey are sucked in rapidly as the bladder expand out. Bladderworts are the fastest movements of all carnivorous plants recorded and can capture their prey within milliseconds. 